\title{
Application of Antioxidative Maillard Reaction Products from Histidine and Glucose to Sardine Products
}

\author{
Munehiko Tanaka, ${ }^{*}$ Chiu Wen Kuei,* Yuji Nagashima,* \\ and Takeshi Taguchi* \\ (Received December 23, 1987)
}

\begin{abstract}
Maillard reaction products (MRP) were prepared by refluxing the mixture of L-histidine and D-glucose (1: 3 molar ratio) in $0.1 \mathrm{M}$ phosphate buffer $(\mathrm{pH} 5,7$, and 9) for up to $24 \mathrm{~h}$. It was found that antioxidative effect of MRP increased as a function of reaction time, particularly at the later stage of the reaction. At higher initial $\mathrm{pH}$, antioxidative effect of MRP became significant. It was also revealed that antioxidative effect exponentially increased as a function of the development of reducing power. MRP also retarded autoxidation of sardine oil, but their antioxidative effect to sardine oil was less than that to linoleic acid. Since POV of sardine oils which had been already oxidized (POV about 50 or 100) was decreased to some extent by the addition of MRP, it was suggested that MRP worked as peroxide destroyers besides autoxidation-breakers. Application of MRP (pH 9, $24 \mathrm{~h}$ heating) to Kamaboko-type sardine products (boiled or deep-fried) was also performed. MRP were mixed in sardine minced meats at the levels of $0-5 \%$ and the products were stored at $4^{\circ} \mathrm{C}$. It was found that MRP effectively inhibited autoxidation of sardine products during storage.
\end{abstract}

Polyunsaturated fatty acids in foodstuffs are particularly prone to autoxidation, which plays a crucial role in the development of rancidity. The oxidation of fatty acids at first leads to the formation of fatty acid hydroperoxides by a free radical chain reaction. The hydroperoxides subsequently undergo several reactions which bring about the formation of such products as aldehydes, ketones, and other volatile compounds. As a result, rancid flavor is developed and limits the shelflife of many food products.

The progress of lipid oxidation can be prevented or retarded either by the use of antioxidants or by packaging in vacuum or inert gas. Synthetic antioxidants such as butylated hydroxyanisole (BHA), butylated hydroxytoluene (BHT) and propyl gallate have sometimes been added to foods. However, from a food hygienic point of view, natural antioxidants are preferred. In recent years a great number of Maillard reaction products (MRP) proved to be effective as antioxidants in model and food systems, ${ }^{1-3}$ ) and might be of special importance since they are so widespread in foods. Despite of a number of study ${ }^{4-7)}$ carried out on antioxidative activity of MRP, no antioxidative compounds formed by the reaction have so far been identified, nor has the mechanism of their antioxidative effect been completely elucidated.

The aims of this work were to study the development of antioxidative activity during the Maillard reaction between histidine and glucose and to apply histidine-glucose MRP to sardine oil and Kamaboko-type sardine products as antioxidants.

\section{Materials and Methods}

\section{Preparation of $M R P$}

L-Histidine monohydrochloride monohydrate (Nihon Rikakagaku Yakuhin Co., Ltd.) and anhydrous D-glucose (Kokusan Kagaku Co., Ltd.) were used for the experiments. MRP were obtained by refluxing $100 \mathrm{ml}$ of $0.1 \mathrm{M}$ potassium phosphate buffer ( $\mathrm{pH} \mathrm{5,7,9)} \mathrm{containing} 33.3$ mmol histidine and $100 \mathrm{mmol}$ glucose for up to $24 \mathrm{~h}$. Initial $\mathrm{pH}$ values were adjusted with potassium hydroxide. Aliquots of $10 \mathrm{ml}$ were withdrawn at $0,0.5,1,3,6,10,24 \mathrm{~h}$, and all samples were stored at $-20^{\circ} \mathrm{C}$ until used.

\section{Analytical Procedures}

Development of brown color during refluxing was measured by the absorption of the reaction

* Department of Food Science and Technology, Tokyo University of Fisheries, Konan, Minato, Tokyo 108, Japan (田中宗彦, 邱 文责, 長島裕二, 田口 武: 東京水産大学食品生産学科). 
mixture at $420 \mathrm{~nm}$ (UV-Visible Recording Spectrophotometer UV-160, Shimadzu Seisakujo Co., Ltd.).

The determination of reducing power was performed by the method reported by Adachis ${ }^{\text {s) }}$ using ferricyanide as a coloring reagent. Reducing power of the reaction mixtures was determined after an appropriate dilution, and expressed as the absorbance at $700 \mathrm{~nm}$.

The antioxidative activities of the reaction mixtures were estimated by comparing the peroxide values (POV) of the samples with that of control according to the procedure of Kirigaya et al. (4) $^{4}$ with slight modifications. To the mixture of $0.5 \mathrm{~g}$ of linoleic acid (minimum $95 \%$ purity, Tokyo Kasei Kogyo Co., Ltd.), $10 \mathrm{ml}$ of carbonyl-free ethanol and $14 \mathrm{ml}$ of $0.2 \mathrm{M}$ phosphate buffer $(\mathrm{pH}$ 7) was added $1 \mathrm{ml}$ of the browning reaction solution. For the control test, $1 \mathrm{~m} l$ of distilled water was used instead of the browning solution. After linoleic acid was completely dissolved in ethanol, the homogeneous mixture was easily prepared by moderate stirring with the buffer solution. The resulting mixture was then incubated at $45^{\circ} \mathrm{C}$ in a tightly stoppered $50 \mathrm{ml}$ flask. The head space volume $(25 \mathrm{~m} l)$ of the flask was kept constant during the incubation. Peroxides formed during incubation were extracted with chloroform and determined by iodometric method. ${ }^{\text {g) }}$ As samples, 10-, 100-, and 1000-fold diluted solutions of MRP were also prepared and their antioxidative activities to autoxidation of linoleic acid were determined.

\section{Application of MRP to Sardine Oil}

Sardines Sardinops melanosticta with the average body weight of $84 \mathrm{~g}$ were used throughout this study. Heads, fins, viscera, bones and skins were removed prior to the extraction of oil. Sardine oil was extracted with chloroform and methanol mixture (2:1) according to Bligh and Dyer method. ${ }^{10)}$ Oil content of sardine meat was approximately $9 \%$.

In order to determine the ability of MRP to prevent the autoxidation of sardine oil, $0.5 \mathrm{~g}$ of oil thus extracted was dissolved in $24 \mathrm{ml}$ of chloroform-methanol mixture $(1: 2)$ to which $1 \mathrm{ml}$ of MRP solution was added. The homogeneous mixture was incubated at $45^{\circ} \mathrm{C}$ and POV was determined periodically as described above. POV of sardine oil per se was approximately 3.5 .

Application of MRP to Kamaboko-type Sardine
Products volumes of ice-cold $0.2 \% \mathrm{NaHCO}_{3}$ for $10 \mathrm{~min}$. The washed meat was centrifuged and adjusted to a moisture content of $84-85 \%$. Sardine meat thus prepared was ground with $2 \%$ salt and $0-5 \%$ MRP (pH 9, $24 \mathrm{~h}$ heating solution) by weight. The meat paste wrapped with polyvinylidene chloride film was heated at $80^{\circ} \mathrm{C}$ for $20 \mathrm{~min}$. After heating, the gels formed were cooled in icewater for $30 \mathrm{~min}$. The products (called "Tsumire" in Japanese) were stored at $4^{\circ} \mathrm{C}$ and POVs of oil extracted were measured periodically during storage.

A part of sardine meat pastes was deep-fried at $140^{\circ} \mathrm{C}$ for $3 \mathrm{~min}$ in salad oil (POV approximately 0.2, Nisshin Oil Mills Ltd.). POV of oil extracted from these products (called "Satsuma-age" in Japanese) kept at $4^{\circ} \mathrm{C}$ was measured periodically.

\section{Results and Discussion}

\section{Development of Antioxidative Activity}

The development of antioxidative activities of MRP prepared by refluxing the mixture of histidine and glucose at initial pH 7 is shown in Fig. 1. POV of linoleic acid at the beginning of the incubation was approximately 6 . It is obvious from Fig. $1(0 \mathrm{~h}$ heating) that POV of linoleic acid alone increased significantly for the period of 3 days at $45^{\circ} \mathrm{C}$ (Control, dotted lines). The increase of POV was faster than that of the control when glucose was added to linoleic acid. On the other hand, histidine per se showed slight antioxidative activity. It is agreeable with results reported by Marcuse $^{11}$ and Karel et al., ${ }^{12)}$ and this was one of reasons why histidine was used as a reactant for the Maillard reaction in this study.

In order to compare antioxidative activities of MRP prepared under various conditions, the term "antioxidative effect", expressed as days required for POV to reach 150, was used throughout this study. That is, the larger the antioxidative effect, the stronger the ability to retard the autoxidation of linoleic acid. Three different dilutions (10, 100-, and 1000-fold) of MRP were also prepared and their antioxidative effects were determined. Table 1 summarizes antioxidative effects of MRP prepared from histidine and glucose under various conditions. It is obvious that antioxidative effects of MRP increased as a function of the reaction time at any $\mathrm{pH}$ studied. Antioxidative effect of MRP became significant particularly after heating of 6-10 h, corresponding to the later stage of the reaction. This may indicate that the formation of polymerized brown pig. 

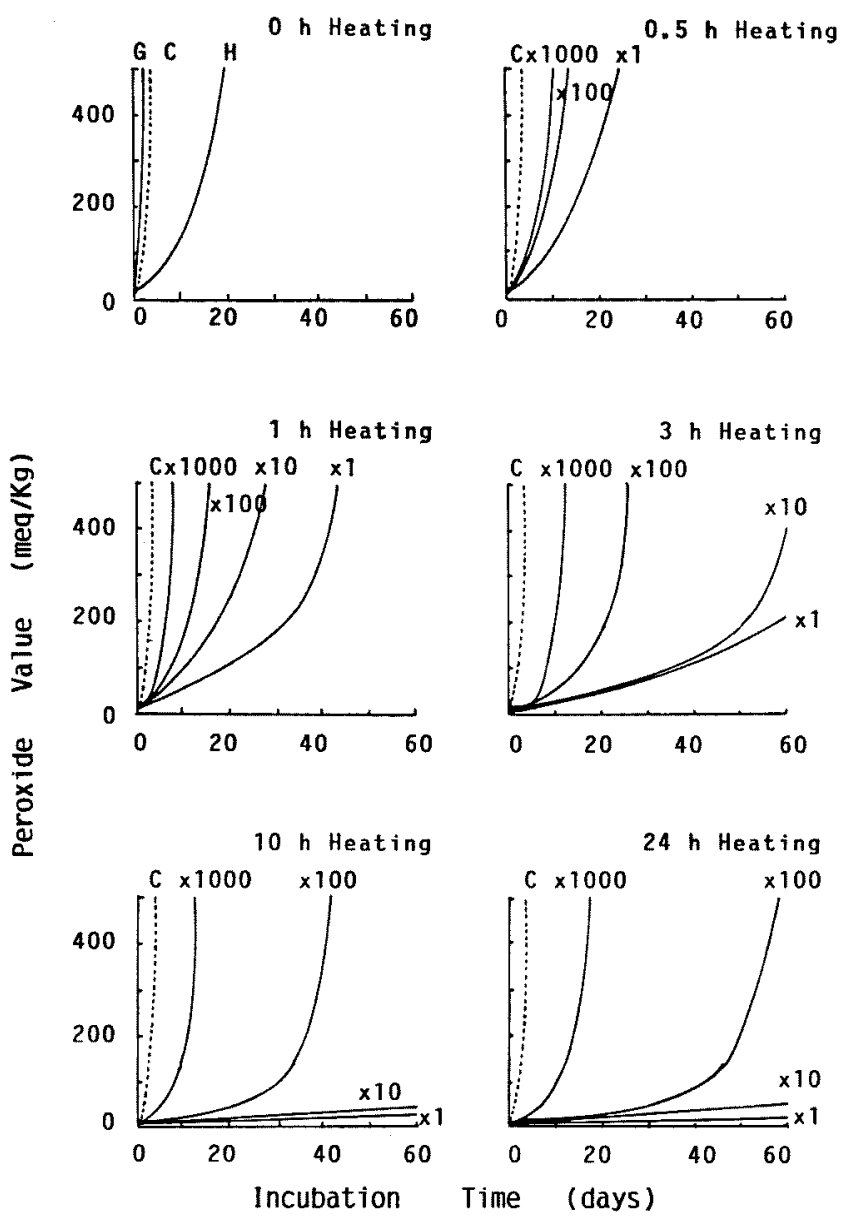

Fig. 1. Antioxidative activity of histidine-glucose reaction mixture (initial pH 7) as a function of heating time. $\mathrm{C}$ : Control, $\mathrm{G}$ : Glucose, $\mathrm{H}$ : Histidine.

ments is at least responsible for the development of antioxidative activity. This was already confirmed by Yamaguchi and Fujimaki ${ }^{13}{ }^{14}$ in glycinexylose model system. They carried out the fractionation of MRP prepared at $100^{\circ} \mathrm{C}$ for $2 \mathrm{~h}$ by Sephadex G-15 gel filtration. As a result, antioxidative activity was observed only in high molecular weight fraction (melanoidins).

Table 1 also presents the influence of initial $\mathrm{pH}$ of the model system on antioxidative effect of MRP obtained. It is apparent that antioxidative effect of MRP became stronger at higher initial $\mathrm{pH}$ at a given heating time. The influence of initial $\mathrm{pH}$ on antioxidative effect was more pronounced particularly after $10 \mathrm{~h}$ of reaction. From these results, it can be concluded that the formation of antioxidative MRP was especially favored by basic pH. These findings were in good agreement with those reported by Kirigaya et al.,5) and Lingnert and Eriksson. ${ }^{15)}$

Antioxidative activity of MRP has been shown to be concomitant with the development of reducing power by some researchers. ${ }^{18-18)}$ A logarithm plot of antioxidative effect of MRP (100-fold dilution) against reducing power yielded a straight line at initial pHs 5, 7, and 9, respectively (Fig. 2). Antioxidative effect of MRP exponentially increased as a function of the reducing power development, suggesting that it could be possible to estimate antioxidative effect by simply determining reducing power of MRP prepared. The mechanism of antioxidative activity development by the Maillard reaction between histidine and glucose may be somewhat different with the initial $\mathrm{pH}$ value of the model system, since antioxidative effect of MRP having the same reducing power 
Table 1. Antioxidative effect of Maillard reaction products from histidine and glucose

\begin{tabular}{|c|c|c|c|c|c|c|}
\hline \multirow{2}{*}{$\begin{array}{c}\text { Initial } \\
\mathrm{pH}\end{array}$} & \multirow{2}{*}{$\begin{array}{l}\text { Heating } \\
\text { time (h) }\end{array}$} & \multirow{2}{*}{$\begin{array}{c}\text { Color } \\
\text { intensity*1 }\end{array}$} & \multicolumn{4}{|c|}{ Antioxidative effect*2 } \\
\hline & & & $\times 1$ & $\times 10$ & $\times 100$ & $\times 1000$ \\
\hline \multirow{6}{*}{5.0} & 0.5 & 1.5 & 10 & 8 & 6 & 3.5 \\
\hline & 1 & 9.5 & 22 & 13 & 7.5 & 5 \\
\hline & 3 & 86.5 & 38 & 30 & 15 & 7.5 \\
\hline & 6 & 223.5 & 77 & 61 & 24 & 12 \\
\hline & 10 & 349.0 & 126 & 97 & 32 & 14 \\
\hline & 24 & 706.0 & 162 & 145 & 43 & 17 \\
\hline \multirow{7}{*}{7.0} & 0.5 & 19.5 & 12 & 9.5 & 7.5 & 5 \\
\hline & 1 & 54.0 & 25 & 14 & 10 & 6.5 \\
\hline & 3 & 160.0 & 48 & 42 & 17 & 9 \\
\hline & 6 & 219.0 & 95 & 74 & 29 & 9.5 \\
\hline & 10 & 302.5 & 151 & 112 & 33 & 10 \\
\hline & 24 & 259.5 & 209 & 160 & 47 & 12.5 \\
\hline & 0.5 & 37.5 & 25 & 21 & 9 & 6.5 \\
\hline \multirow{5}{*}{9.0} & 1 & 69.0 & 41 & 32 & 13.5 & 10 \\
\hline & 3 & 158.5 & 75 & 61.5 & 25 & 13 \\
\hline & 6 & 258.5 & 134 & 115 & 41 & 18 \\
\hline & 10 & 336.5 & 170 & 148 & 54 & 18.5 \\
\hline & 24 & 420.5 & 218 & 180 & 70 & 22 \\
\hline
\end{tabular}

- 1 Absorbance at $\mathbf{4 2 0} \mathrm{nm}$ after reaction.

*2 Defined as days for POV to reach 150 at incubation of $45^{\circ} \mathrm{C}$.

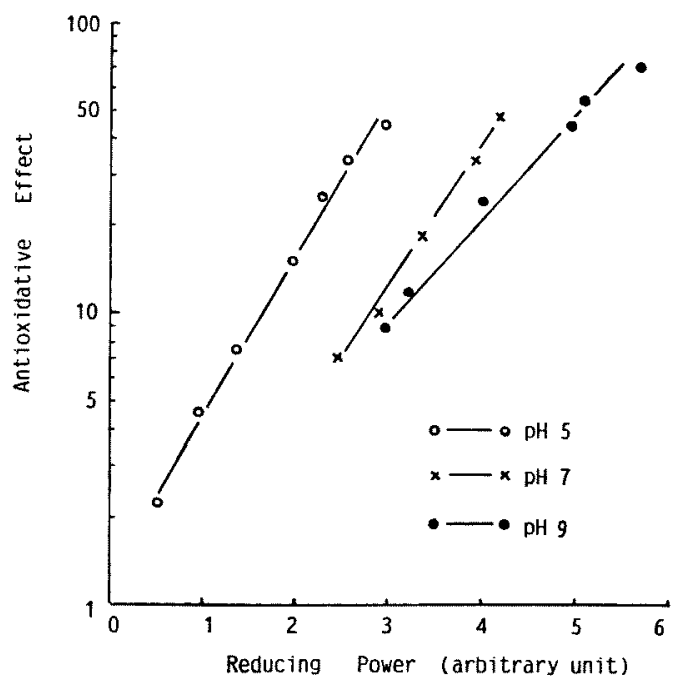

Fig. 2. Relationship between reducing power of histidine-glucose reaction mixture (100-fold dilution) and antioxidative effect.

varied with the starting $\mathrm{pH}$ value.

\section{Application of MRP to Sardine Oil}

Fig. 3 shows antioxidative activities of MRP prepared by heating histidine and glucose for $24 \mathrm{~h}$ at pHs 5, 7, and 9 (10- and 100-fold dilution) to sardine oil at the incubation of $45^{\circ} \mathrm{C}$. POV development of control (sardine oil alone) pro- ceeded at a slower rate than that of linoleic acid alone, indicating the presence of indigenous natural antioxidants coextracted together with oil from sardine meat. As given in Fig. 3, MRP retarded autoxidation of sardine oil and their antioxidative activities were stronger with higher initial pH. However, antioxidative effects of MRP ( $24 \mathrm{~h}$ heating) to sardine oil were 23 at $\mathrm{pH} 5,34$ at $\mathrm{pH} 7$, and 40 at $\mathrm{pH} 9$ (100-fold dilution); 104 at

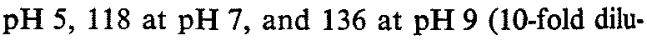
tion). Those values were less than those to linoleic acid (Table 1). It could be owing to facts that sardine oil contains a large amount of highly unsaturated fatty acids such as eicosapentaenoic acid (EPA) and docosahexaenoic acid (DHA), which are more prone to autoxidation than linoleic acid.

In the next experiment, MRP ( $\mathrm{pH} \mathrm{5,} \mathrm{7,} \mathrm{and} \mathrm{9,}$ $24 \mathrm{~h}$ heating, 10-fold dilution) were added to sardine oil which had POVs about 49 or 109. Peroxide values of sardine oils dropped to 33-39 in the former and 91-98 in the latter. These results indicate that MRP can work to some extent as peroxide destroyers which react with hydroperoxides to give stable products by nonradical processes besides autoxidation-breakers which interfere with the free radical chain reaction. ${ }^{10)}$

There are several reports having been published pertaining to the application of antioxidative MRP to vegetable and animal lipids such as 


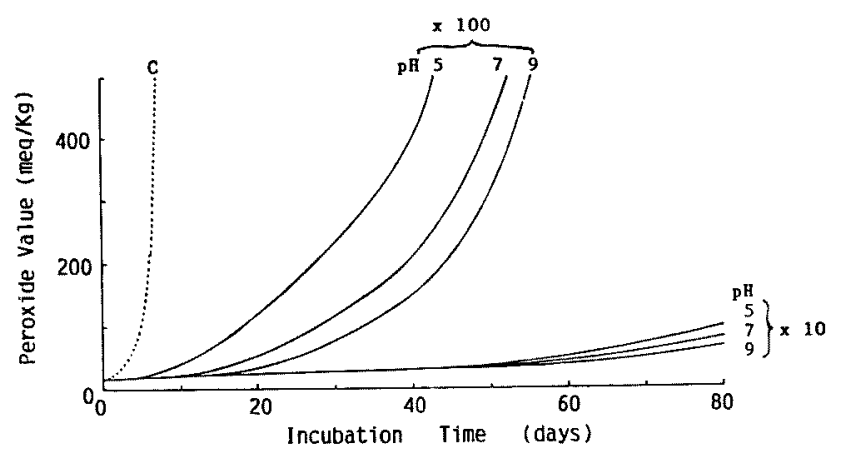

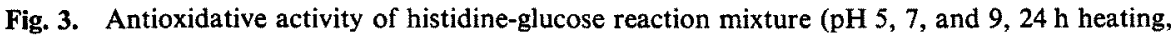
10- and 100-fold dilution) to sardine oil. The mixture of sardine oil and MRP was incubated at $45^{\circ} \mathrm{C}$.

soybean oil, ${ }^{(8)}$ cottonseed oil, ${ }^{18,20)}$ corn oil, ${ }^{18)}$ and lard. ${ }^{21}$ With reference to fish oil, Tarr and Cooke ${ }^{22)}$ reported that enediols, intermediate products of the Maillard reaction, strongly retarded fat oxidation in frozen minced salmon or herring meats stored at -10 or $-20^{\circ} \mathrm{C}$. Although investigations of MRP as antioxidants have shown exceptionally potent antioxidative activity to a variety of vegetable and animal lipids, the practical use of MRP as an antioxidant in food industry has not been so far carried out. This could owe to facts that MRP have their own characteristic dark color, bitter taste and peculiar flavor. The most troublesome problem about the application of MRP as antioxidants is their limited solubility in lipids, so that it is rather difficult to use MRP for edible fats and oils.

\section{Application of MRP to Kamaboko-type Sardine Products}

Though various antioxidative MRP have been applied to processing and storage of foods, such as cookies, ${ }^{23)}$ cereals, ${ }^{24)}$ sausage, ${ }^{23)}$ and cooked meats, ${ }^{2 \theta)}$ there is little work reported on the use of antioxidative MRP for fish meat products which are rich in highly unsaturated fatty acids.

In this experiment, sardine minced meats mixed with MRP from histidine and glucose ( $\mathrm{pH} \mathrm{9,24} \mathrm{h}$ heating solution, $0-5 \%$ by weight) together with $2 \%$ salt were boiled or deep-fried. Table 2 shows effect of MRP on POV development of the products during $4^{\circ} \mathrm{C}$ storage. Autoxidation of boiled Kamaboko-type sardine products was almost completely inhibited by the addition of MRP at $0.1 \%$ level during the storage of 4 days. It is noteworthy that the effect of MRP was quite remarkable at 2 or $5 \%$ level even after the storage of 11 days. The only problem for the production of boiled sardine products concerning the use of MRP at these levels was that the color of the products became darker by MRP. From this point, it would be better if effective colorless antioxidants

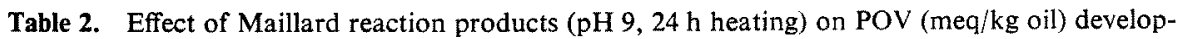
ment of boiled ${ }^{* 1}$ and deep-fried ${ }^{* 2}$ Kamaboko-type sardine products during storage at $4^{\circ} \mathrm{C}$

\begin{tabular}{|c|c|c|c|c|c|c|c|c|}
\hline \multirow{2}{*}{ Product } & \multirow{2}{*}{$\begin{array}{l}\text { Storage } \\
\text { time } \\
\text { (days) }\end{array}$} & \multicolumn{7}{|c|}{ Amount of MRP added $(\%)^{* 3}$} \\
\hline & & 0 & 0.1 & 0.2 & 0.5 & 1.0 & 2.0 & 5.0 \\
\hline \multirow{4}{*}{ Boiled } & 0 & 7.8 & 3.6 & 3.2 & 3.4 & 3.6 & 3.3 & 3.3 \\
\hline & 4 & 11.2 & 4.5 & 4.3 & 3.6 & 3.4 & 3.5 & 3.1 \\
\hline & 7 & 50.8 & 26.0 & 25.1 & 23.8 & 19.2 & 8.3 & 3.4 \\
\hline & 11 & 147.0 & 38.4 & 34.8 & 27.3 & 22.7 & 17.0 & 5.9 \\
\hline \multirow{4}{*}{ Deep-fried } & 0 & 5.5 & 2.8 & 2.4 & 2.4 & 2.3 & 2.4 & 1.9 \\
\hline & 1 & 14.3 & 11.1 & 10.2 & 8.9 & 7.8 & 4.0 & 3.1 \\
\hline & 5 & 42.3 & 22.6 & 20.2 & 19.5 & 15.5 & 10.4 & 6.5 \\
\hline & 8 & 76.4 & 47.9 & 34.0 & 33.0 & 24.4 & 19.8 & 9.2 \\
\hline
\end{tabular}

*1 Washed sardine minced meats were heated at $80^{\circ} \mathrm{C}$ for $20 \mathrm{~min}$.

*2 Washed sardine minced meats were deep-fried at $140^{\circ} \mathrm{C}$ for $3 \mathrm{~min}$.

* MRP (pH 9, 24 b heating solution) were added by weight into washed sardine minced meats together with $2 \%$ salt. 
are prepared or isolated from MRP.

POV of deep-fried products at the start of the storage was smaller than that of boiled products (Table 2). On the other hand, deep-fried sardine products without the addition of MRP (control) exhibited faster POV development during storage than that of boiled sardine products. Effect of MRP addition on POV development of deep-fried products was related to the amount of MRP added, but was somewhat less than that on boiled products. Anyway, it is clear from Table 2 that MRP is also effective as antioxidants to deep-fried sardine products. Further examination of the heat-stability of MRP would be necessary prior to the application of MRP to products which are processed at higher temperatures.

\section{References}

1) N. Yamaguchi: Yukagaku, 30, 111-117 (1969).

2) H. Kato: Shokuhin Eiseigaku Zasshi, 14, 343351 (1973).

3) N. Yamaguchi: Food Chemical, No. 9, 51-61 (1985).

4) N. Kirigaya, H. Kato, and M. Fujimaki: Agric. Biol. Chem., 32, 287-290 (1968).

5) N. Kirigaya, H. Kato, and M. Fujimaki: Nippon Nogeikagaku Kaishi, 43, 484-491 (1969).

6) N. Yamaguchi and M. Fujimaki: Nippon Shokuhin Kogyo Gakkaishi, 20, 507-512 (1973).

7) T. D. Obretenov, M. J. Kuntcheva, and I. N. Panchev: J. Food Process. Preserv., 10, 251-268 (1986).

8) S. Adachi: Nippon Nogeikagaku Kaishi, 32, 313316 (1958).

9) "Official Methods of Analysis of A. O. A. C." (ed. by W. Horwitz), eleventh ed., A. O. A. C., Washington D. C., 1970, p. 445.
10) E. G. Bligh and W. J. Dyer: Can. J. Biochem. Physiol., 37, 911-917 (1959).

11) R. Marcuse: J. Am. Oil Chemists' Soc., 39, 97103 (1962).

12) M. Karel, S. R. Tannenbaum, D. H. Wallace, and H. Maloney: J. Food Sci., 31, 892-896 (1966).

13) N. Yamaguchi and M. Fujimaki: Nippon Shokuhin Kogyo Gakkaishi, 17, 136-141 (1970).

14) N. Yamaguchi and M. Fujimaki: Nippon Shokuhin Kogyo Gakkaishi, 17, 142-147 (1970).

15) H. Lingnert and C. E. Eriksson: J. Food Process. Preserv., 4, 161-172 (1980).

16) C. D. Evans, H. A. Moser, P. Cooney, and J. E. Hodge: J. Am. Oil Chemists' Soc., 35, 84-88 (1958).

17) N. Yamaguchi and Y. Koyama: Nippon Shokuhin Kogyo Gakkaishi, 14, 106-109 (1967).

18) N. Kirigaya, H. Kato, and M. Fujimaki: Nippon Nogeikagaku Kaishi, 45, 292-298 (1971).

19) C. K. Park and D. H. Kim: J. Am. Oil Chemists' Soc., 60, 98-102 (1983).

20) M. M. A. Soliman, H. M. Fadel, A. A. El-Sawy, and S. G. Donia: Hungarian J. Ind. Chem., 14, 99-103 (1986).

21) N. Yamaguchi: Nippon Shokuhin Kogyo Gakkaishi, 16, 94-96 (1969).

22) H. L. A. Tarr and N. E. Cooke: J. Fish. Res. Bd. Canada, 7, 522-527 (1949).

23) H. Lingert: J. Food Process. Preserv., 4, 219-233 (1980).

24) R. H. Anderson, D. H. Moran, T. E. Huntley, and J. L. Holahan: Food Technol., 17, 15871592 (1963).

25) H. Lingnert and B. Lundgren: J. Food Process. Preserv., 4, 235-246 (1980).

26) K. Sato, G. R. Hegarty, and H. K. Herring: $J$. Food Sci., 38, 398-400 (1973).

27) R. Beckel, H. Lingnert, B. Lundgren, G. Hall, and G. R. Waller: J. Food Sci., 50, 501-502, 530 (1985). 